\title{
Subcutaneous Model for the Study of Dengue Virus Infection in Immune Competent Mice
}

\section{Beatriz Senra Santos ${ }^{1}$, Natalia Lima Pessoa ${ }^{1,2}$, Natalia Lucinda1,3, Gustavo Cardoso de Oliveira ${ }^{1}$, Thais Souza Silva ${ }^{1}$, Ketyllen Reis Andrade ${ }^{1}$, Bruno Galvão Filho', Marcele Neves Rocha ${ }^{1}$, Alexandre Vieira Machado ${ }^{1}$, Pedro Augusto Alves ${ }^{1}$, Érica Alessandra Rocha Alves ${ }^{1}$, Erna Geessien Kroon ${ }^{*}$, Marco Antônio Campos ${ }^{{ }^{*} \#}$}

${ }^{1}$ Instituto René Rachou, Fundação Oswaldo Cruz, Fiocruz, Belo Horizonte, Brazil

${ }^{2}$ Departamento de Microbiologia, Universidade Federal de Minas Gerais, Belo Horizonte, Brazil

${ }^{3}$ Empresa Brasileira de Pesquisa Agropecuária, Laboratório de Virologia, Brasilia, Brazil

Email: "marcoasc@minas.fiocruz.br

How to cite this paper: Santos, B.S., Pessoa, N.L., Lucinda, N., de Oliveira, G.C., Silva, T.S., Andrade, K.R., Filho, B.G., Rocha, M.N., Machado, A.V., Alves, P.A., Alves, É.A.R., Kroon, E.G. and Campos, M.A. (2018) Subcutaneous Model for the Study of Dengue Virus Infection in Immune Competent Mice. Journal of Biosciences and Medicines, 6, 97-110. https://doi.org/10.4236/jbm.2018.65011

Received: March 31, 2018

Accepted: May 21, 2018

Published: May 24, 2018

Copyright (c) 2018 by authors and Scientific Research Publishing Inc. This work is licensed under the Creative Commons Attribution International License (CC BY 4.0).

http://creativecommons.org/licenses/by/4.0/ (c) (i) Open Access

\begin{abstract}
Various mouse models to study dengue have been described by different authors, some of them using immunodeficient or some using humanized mice. Our group reported previously a deadly murine model, which used the intracranial inoculum of highly virulent Dengue virus (DENV) in immune competent mouse. Here we present a model of immune competent mouse (C57BL/6), infected subcutaneously by the same highly virulent DENV (DENV3 genotype I). In this immunocompetent systemic mice model, the cytokine levels and hematological parameters such as total and differential leukocyte and platelets counts, together with weight loss, were considered important monitoring parameters, allowing a better understanding of the systemic human disease. Mice were inoculated subcutaneously and evaluated by the percentage weight variation as well as the clinical signs. Hematological parameters and cytokines levels were measured and viral titration in brain tissue or serum neutralization was performed to confirm mice infection. The subcutaneously DENV inoculated mice showed weight loss after infection, but they did not show any other clinical signs. The leukocytes and platelets decreased after subcutaneous inoculation. The cytokines TNF alpha and IFN gamma increased after infection in mice. The subcutaneous model provided scope for improved understanding of the dengue pathogenesis, as well as possible mechanism for protection to subsequent mouse infected by intracranial route in mice. This model could be used to study the vertebrate immune response and evaluation of drugs or vaccine against dengue virus.
\end{abstract}

*These authors contributed equally to this work. 


\section{Keywords}

Subcutaneous Murine Model, Dengue Disease, Immune Competent Mouse, Cytokines, Innate Immune Response

\section{Introduction}

Dengue, one of the most prevalent infectious diseases in the $21^{\text {st }}$ century [1], is a mosquito-borne viral disease. Dengue is a febrile disease of acute evolution caused by the dengue virus (DENV) of the Flaviviridae family, and it infects humans through the bite of the female hematophagous mosquito Aedes aegypti [2]. Patients often develop a sudden high fever after the incubation period. This acute febrile phase usually lasts $2-7$ days and is often accompanied by several symptoms, such as headaches, chills, retro-orbital pain, and myalgia. Dengue was classified by the World Health Organization as occurring with or without warning signs or as severe dengue [3] [4].

One of the possible warning signs is the impairing of consciousness (neurological disease) caused by DENV, which may include symptoms such as severe headache, neck stiffness, reduced consciousness and seizures. Although not very common to date, neurological disease caused by DENV is more frequently described in the last years and is a severe disease. However, the cause of this neurovirulence is still unclear [5] [6] [7] [8] [9]. In animal model, the uses of hematological parameters such as differentiation and counting of total leukocytes, red blood cells, platelets, lymphocytes, neutrophils and monocytes [10] [11] [12] [13] are important disease markers, allowing a better understanding of dengue disease and its response mechanisms in the body of the animals studied [5] [14] [15] [16] [17]. Additionally, cytokines such as IFN gamma, TNF alpha and IL12p70 are used to evaluate the immune response to DENV infection [18] [19] [20].

Three different approaches are found in the literature, focusing on the induction of a human-like disease in any of: 1) immunocompetent mice [6], 2) mice deficient in specific genes that are important for the immune response and are naturally absent or have been removed [17] [21] [22], and 3) immunodeficient mice that had been implanted with human cells [6] [21] [22].

Our group reported previously an intracranial inoculum of a highly virulent DENV in immune competent mouse, causing death [6]. However, this model was very aggressive with the death of the mice in 9 days with neurological signs. Here we present a model of immune competent mouse (C57BL/6) infected subcutaneously mimicking the natural way of infection by the same highly virulent DENV (DENV3 genotype I) used previously [6] [21]. This allowed the understanding of some additional steps of the pathogenesis, and showed that the subcutaneous infection conferred protection to a second infection by an intracranial via. 


\section{Material and Methods}

\subsection{Virus}

DENV3 genotype I (MG20), which is highly virulent for mice, was obtained from virus collection of Laboratório de Vírus of Universidade Federal de Minas Gerais (UFMG), Belo Horizonte, MG, Brazil. It was isolated from a patient presenting neurological manifestations of dengue and death [23]. The virus used in this study was a virus with only 6 passages in C6/36 cells, thus maintaining the initial highly virulent characteristics of the virus.

\subsection{Cells}

C6/36 cells is a continuous lineage obtained from Aedes albopictus (ATCC, number CRL-1660) larvae and were cultivated on Leibovitz (L-15) medium (Gibco, USA), containing ciprofloxacin at $10 \mu \mathrm{g} / \mathrm{mL}$ and fetal bovine serum (FBS) at $10 \%$ (Cultilab, Brazil). Cells were maintained in BOD at $28^{\circ} \mathrm{C}$. For the passage of cell monolayers, culture medium was discarded and cells washed with phosphate buffer saline (PBS), pH 7,2 and then homogenized in L15 medium (Gibco, USA) and distributed into 25 or $75 \mathrm{~cm}^{2}$ culture flasks. C6/36 cells were used to study viral replication. BHK-21 cells derived from hamster kidney (ATCC, number CCL-10) were cultivated on Dulbecco's Modified Eagle Medium (DMEM, Gibco, USA), containing gentamicin at $50 \mu \mathrm{g} / \mathrm{mL}$, penicillin at $100 \mathrm{IU} / \mathrm{mL}$, amphotericin $\mathrm{B}$ at $5 \mu \mathrm{g} / \mathrm{mL}$ and $\mathrm{FBS}$ at $5 \%$. Cells were maintained in a $\mathrm{CO}_{2}$ cell incubator at $37^{\circ} \mathrm{C}$. BHK cells were used in viral titration protocol and serum neutralization test.

\subsection{Mice}

Immune competent C57BL/6 mice were provided by animal facilities of Instituto René Rachou-Fiocruz-MG (IRR). The animals, all males, were 8 weeks old.

\subsection{Animal Research}

This project was submitted to and approved by the Ethical Committee of Animal Handling (CEUA) from Fundação Oswaldo Cruz, Fiocruz, Brazil (LW-7/16), see annex 1. This study was carried out in strict accordance with the recommendations of the Brazilian National Council for Control of Animal Research (CONCEA).

\subsection{Criteria Used to Determine Mice Euthanasia}

In previous publication we demonstrated that mice inoculated by intracranial route with highly virulent virus presented clinical signs of disease as loss of weight, lethargy, ruffled fur, hunched posture and paralysis of paws, and since then it has been established by our group that the mice with these clinical signs should be immediately euthanized [6]. These criteria were described in the project submitted and approved by the Ethical Committee of Animal Handling described above. 
Additionally the infected or mock mice were euthanized at the end of each experiment. No animal died before meeting the euthanasia criteria or before the end of the experiment.

\subsection{Animal Welfare}

Animals were maintained in micro isolators on ventilated shelves at IRR's animal facilities, where the temperature $\left(23^{\circ} \mathrm{C} \pm 2^{\circ} \mathrm{C}\right)$, humidity, ventilation, sanitation and illumination were controlled. Food and water were provided ad libitum. Mice received subcutaneous inoculum (SC) containing $5 \times 10^{4}$ p.f.u. of DENV 3 genotype I (MG20) on a final volume of $100 \mu \mathrm{L}$. The animals were monitored daily for evaluation of clinical signs and survival curve and weighed daily. All cages had igloos as environmental enrichment for animals. All those involved in the handling of the animals were previously trained by the IRR's animal facilities.

\subsection{Models of Infection}

Subcutaneous infection (SC) - the mice received inoculum of $5 \times 10^{4}$ p.f.u. of DENV by SC route (inoculum of $100 \mathrm{uL}$ ); Intracranial infection (IC) - the mice received inoculum of 400 p.f.u. of DENV by IC route (inoculum of $10 \mathrm{uL}$ ); Subcutaneous infection followed by intracranial infection (SC-IC) - the mice received $5 \times 10^{4}$ p.f.u. of virus (inoculum of $100 \mathrm{uL}$ ) and after 14 days received new infection by IC route with 400 p.f.u. of virus (inoculum of $10 \mathrm{uL}$ ); Mock mice-the mice received only inoculum with the C6/36 cell supernatant. Six mice were used in each group.

\subsection{Viral Titration}

BHK-21 cells were used to titer viral stocks and the organs of infected mice. Cell monolayer, $5 \times 10^{5}$ BHK-21 cells were implanted in 6 wells plates with DMEM supplemented with $5 \%$ of heat inactivated FBS (Cultilab, Brazil) and antibiotics, and incubated for 24 hours at $37^{\circ} \mathrm{C}$ in a $5 \% \mathrm{CO}_{2}$ cell incubator. Medium was discarded and cell monolayer was washed once with PBS. Then $400 \mu \mathrm{L}$ of serial dilutions (using $10^{-3}$ to $10^{-7}$ dilutions) of virus to be titrated were added in each well, leaving a well for cell control. After one hour of adsorption the medium was removed and $2 \mathrm{~mL} /$ well of DMEM, containing $1 \%$ of carboxymethylcellulose (CMC) (Sigma, Germany) and $2 \%$ of FBS was added. Cells were incubated at $37^{\circ} \mathrm{C}$ for 6 days at a cell incubator with $5 \%$ of $\mathrm{CO}_{2}$. After 6 days of observation under a microscope, cells were fixed for 1 hour with formaldehyde at $3.7 \%$ diluted in PBS for subsequent staining with crystal violet at $1 \%$ solution for 20 minutes. The number of lysed plaques were counted for titer determination in plaque forming units per milliliter (p.f.u./mL).

\subsection{Plaque Reduction Neutralization Test (PRNT $\left.{ }_{50}\right)$ for DENV-3}

The adapted protocol from Russell et al. [24] was used for serum neutralization 
test. BHK-21 cells were plated at the concentration of $5 \times 10^{4}$ cells $/ \mathrm{ml}$ in 24 well plate $(1 \mathrm{~mL} /$ well) with DMEM supplemented with $5 \%$ of FBS and antibiotics and incubated for 24 hours at $37^{\circ} \mathrm{C}$ in a $5 \% \mathrm{CO}_{2}$ cell incubator. Sera were inactivated at $56^{\circ} \mathrm{C}$ for 30 minutes and diluted $(1: 10,1: 20,1: 40$ : 1:80) in DMEM supplemented with $1 \%$ FBS and incubated with the same volume of diluted virus (50 p.f.u./well) for 1 hour at room temperature. The neutralized sera were added to BHK-21 cells in plates for one hour for adsorption. The serum was removed and $1 \mathrm{~mL}$ DMEM supplemented with 5\% of FBS and 1\% CMC was added in each well and was incubated at $37^{\circ} \mathrm{C}$ for 7 days in a $5 \% \mathrm{CO}_{2}$ cell incubator. After seven days the cells were fixed for one hour with $3.7 \%$ formaldehyde diluted in PBS and subsequently stained with crystal violet (1\%) for 20 minutes. Plaques were counted in wells that received negative serum and, in the wells, which received the test sera. The $\mathrm{PRNT}_{50}$ index was calculated by the highest serum dilution capable of reducing the total number of plaques by $50 \%$, relative to the control.

\subsection{Cytokine Level Detection}

To measure the cytokine levels in brain tissues were collected, macerated and stored on a protease inhibitor solution (complete, Mini, EDTA-free) and 25 $\mu \mathrm{L} /$ well of organ macerate or $25 \mu \mathrm{L}$ of each dilution of standard (including the negative control) were added into a 96 well V-bottom plate. Following, 18 $\mu \mathrm{L} /$ well of the CBA mix (Inflammation BDTM Cytometric Bead Array (CBA) mouse kit [25], USA) was pipetted. Then, $15 \mu \mathrm{L}$ of PE detection reagent was added and it was incubated for 2 hours protected from light. After the incubation period, $100 \mu \mathrm{L}$ of wash buffer was added to each well and centrifuged at 200 $\mathrm{g}$ for 5 minutes. Supernatant was discarded and $150 \mu \mathrm{L} /$ well of wash buffer was added to wash the beads. Samples were read in the FACSCan (BD Biosciences) and the analysis of the CBA was done in the CellQuest software (BD Biosciences), with the results represented in $\mathrm{pg} / \mathrm{mL}$. The cytokine kinetics was chosen based on innate ( 6 and 12 h.p.i. hours post infection) and adaptive immune response ( 8 d.p.i. days post infection) in the host [19] and on the time at which the weight loss begins.

\subsection{Real-Time PCR}

Real-Time PCR was performed to measure levels of virus genomic RNA expression in brain and liver [26] [27]. RNA extracted with TRIzol ${ }^{\circledast}$ reagent was treated with DNAse prior to further reverse transcription. Protocol of RNA treatment with DNAse was according to the RQ1 RNAse-Free DNAse kit instructions (Promega). Procedure for reverse transcription (RT) was performed according to the protocol of the manufacturer (Promega Corporation, USA). For the qPCR, $2.5 \mu \mathrm{L}$ of the cDNA obtained from the RT were used. Each primer $(0.2$ $\mu \mathrm{L}$ ) was aliquoted at $10 \mu \mathrm{M} ; 5.0 \mu \mathrm{L}$ of Power SYBR ${ }^{\circledast}$ Green PCR Master Mix 2X (Applied Biosystems) and $2.0 \mu \mathrm{L}$ of RNAse-free water (Ultra-Pure Distilled Water-Invitrogen) with a final volume of $10.0 \mu \mathrm{L} /$ well was used in a 384 wells plate 
containing SYBR Green I marker, AmpliTaq Gold DNA Polymerase (2 units for reaction), dNTP, buffer and passive reference dyestuff ROX, in Applied Biosystems ViiA 7 apparatus. Amplifications were used with 40 cycles of $95^{\circ} \mathrm{C}$ for 30 seconds and $60^{\circ} \mathrm{C}$ for 1 minute, preceded by $95^{\circ} \mathrm{C}$ for 3 minutes. After the reaction, the amplified specificity was observed, conferring the dissociation temperature (TM) given by the dissociation curve, specific for the target transcript. The following oligonucleotides were used in the reactions: HPRT-hypoxanthine guanine phosphoribosyl transferase (Reverse: 5'-GAT TCA ACT TGC GCT CAT CTT AGG-3'; Forward: 5'-GTT GGA TAC AGG CCA GAC TTT GTT G-3'); DENV-5' URT DENV Non-coding 5' terminal region of the DENV: (Reverse: 5'-TCC GTT GGT TGT TCA TCA GA-3'; Forward: 5'-TCG GAA GCT TGC TTA ACG TAG-3'). Relative quantification methodology was used to analyze the data. Expression of the genomic RNA was normalized to the expression level of the constitutively expressed HPRT gene.

\subsection{Blood Cells Count}

Immediately after anesthesia, blood samples were obtained through brachial plexus and were added on microtainer tubes coated with EDTA (Becton Dickinson Vacutainer Systems, Franklin Lakes, NJ, USA). Red blood cells (diluted in PBS 1:200), platelets (diluted in ammonium oxalate 1:100) and leukocytes (diluted in Turk's blue solution 1:20) counts were performed manually on a Neubauer chamber and monocytes, neutrophils and lymphocytes were counted manually on a previously fixed and stained blood smear slide.

\subsection{Statistical Analysis}

The infected groups were compared to the control group using the Mann-Whitney test for non-parametric samples and T-test for parametric samples. Statistical analyzes were performed utilizing the statistical software GraphPad Prism 5 (GraphPad Software, Inc., La Jolla, CA). Differences were considered significant when $\mathrm{p}<0.05$.

\section{Results}

\subsection{Impact on Weight after Inoculation of DENV3 Genotype I, By Subcutaneous (SC) Route and Protection to a Second Challenge by Intracranial (IC) Route of Infection in Immune Competent Mice}

The C57BL/6 mice were inoculated via intracranial (IC) route with $4 \times 10^{2}$ p.f.u. of DENV 3 genotype I (Figure 1). Clinical signs (weight loss, pilo-erection, hunched posture and hind limb paralysis) were evaluated daily, confirming the susceptibility to neuro-infection of mice by via intracranial (IC) route which developed neuro-encephalitis and death within 9 days after infection, as reported previously [6]. In another model, the same highly virulent DENV and the same strain of mice used in previous studies but inoculated subcutaneously (SC) 


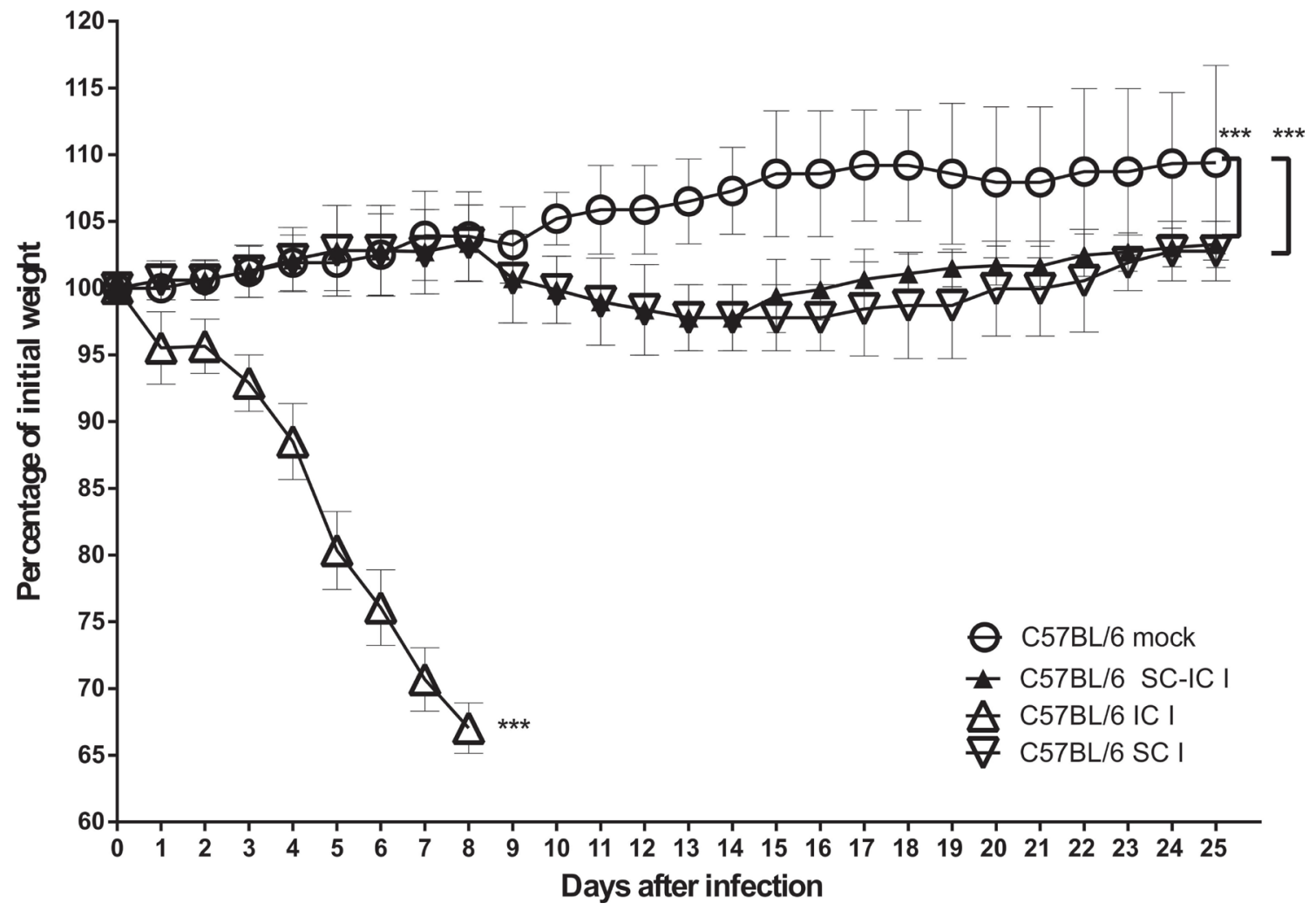

Figure 1. Impact on weight of immune competent mice (C57BL/6) after subcutaneous inoculum of highly virulent DENV. Four groups of mice were used in this experiment: mock mice, subcutaneously infected mice (C57BL/6 SC I), subcutaneously-intracranially infected mice (C57BL/6 SC-IC I), and mice infected by IC route (C57BL/6 IC I), to compare the impact on the survival of both types of inoculums. ${ }^{* * *} \mathrm{p}<0.0001$ when compared C57BL/6 mock $\times$ C57BL/6 SC I, C57BL/6 mock $\times$ C57BL/6 SC-IC on days $15-23$ after infection and C57BL/6 mock $\times$ C57BL/6 IC on days 4 - 8 after infection using t test. d.p.i. = days post infection. Figure representative of three experiments with similar results.

instead IC. This subcutaneously (SC) infection was performed with $5 \times 10^{4}$ p.f.u. and the mice were evaluated daily for the appearance of clinical signs of the disease during the next 25 days (Figure 1).

The infected mice presented a percentage variation of weight gain lower than the uninfected ones. In this model of infection, the animals did not show pilo-erection, hunched posture or hind limb paralysis, and no mouse died, but there was weight loss in infected mice compared to uninfected mice. The infected mice presented this weight loss from day 10 post infection and regained weight from day 18 after infection, maintaining that gain until the end of the experiment.

Firstly, a SC infection was performed with $5 \times 10^{4}$ p.f.u. and on day 14 after this infection, a second infection, now via IC, was performed with $4 \times 10^{2}$ p.f.u. of highly virulent DENV. The variation of weight gain between the infected and the non-infected mice were similar to that in the SC infection and mock SC only. The mock curve was performed with mean of the weights of the mice inoculated separately with C6/36 cell supernatants by the three routes (SC, IC and SC-IC), because the weights were very similar. 
To confirm virus effective infection via IC, SC and SC-IC, virus brain titration, with inoculum via IC or via SC or via SC-IC or serum neutralization via inoculum SC, of infected mice, were performed (Table 1) and also Real Time PCR was performed to confirm the presence of genomic RNA in the brain (infected via IC or SC-IC) or in the liver of the animals infected by SC (Figure 2).

The results confirm that the virus replicated inside the brain in the IC or SC-IC or in the serum via SC infection with a titer of 1.2 to $1.4 \times 10^{4}$ p.f.u. at the $5^{\text {th }}$ day post infection and $29 \times 10^{4}$ p.f.u. at the seventh day post infection (Table 1). There was an antibody response against DENV in the SC infection at a titer of $1: 80$ per $\mathrm{mL}$ at the $60^{\text {th }}$ day post infection (Table 1 ).

\subsection{Changes in Hematological Parameters}

Leukopenia was observed in subcutaneously infected mice on the $8^{\text {th }}$ day after infection when compared to uninfected animals (Figure 3(a)). There was no significant difference in erythrocytes counts in mice (Figure $3(\mathrm{~b})$ ) in any of the times studied when compared to the uninfected ones. Figure 3 (c) shows a decrease in the number of platelets at all times studied in the infected mice when compared to the uninfected mice.

Table 1. Viral titer and serum neutralization.

\begin{tabular}{|c|c|c|c|c|}
\hline \multicolumn{2}{|c|}{$\begin{array}{l}\text { Virus titer p.f.u. } \times 10^{4} \\
\text { (per mg of brain, IC) }\end{array}$} & $\begin{array}{l}\text { Virus titer p.f.u. } \times 10^{4} \\
\text { (per mg of brain, SC-IC) }\end{array}$ & $\begin{array}{l}\text { Virus titer p.f.u. } \times 10^{4} \\
\text { (per mg of serum, SC) }\end{array}$ & $\begin{array}{c}\text { Abs neutralization } \\
\text { (SC) }\end{array}$ \\
\hline $0 \mathrm{dpi}$ & - & - & - & \\
\hline $3 \mathrm{dpi}$ & - & - & - & $0 \mathrm{dpi}<20$ \\
\hline $5 \mathrm{dpi}$ & $1.2( \pm 0.19)$ & $1.4( \pm 0.19)$ & $1.3( \pm 0.19)$ & $60 \mathrm{dpi} \geq 80$ \\
\hline $7 \mathrm{dpi}$ & $29( \pm 1.7)$ & $30( \pm 1.7)$ & $20( \pm 2.5)$ & \\
\hline
\end{tabular}

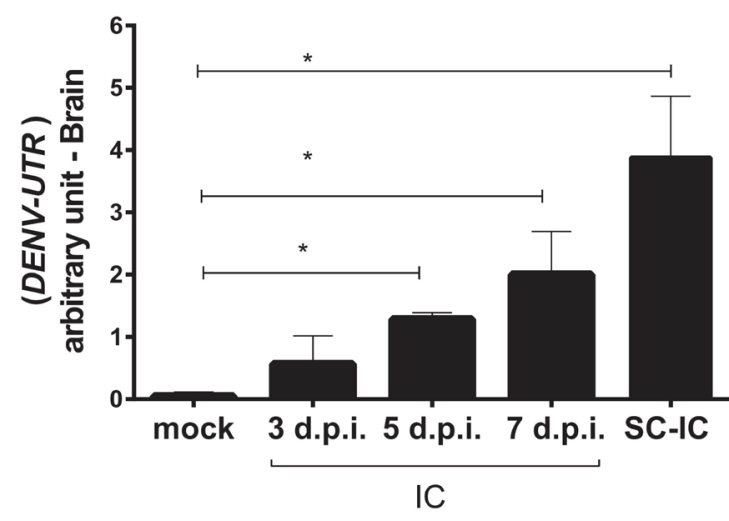

(a)

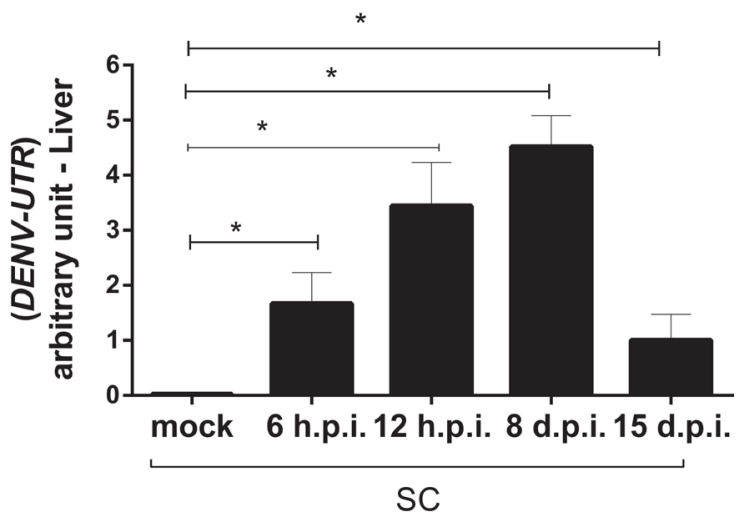

(b)

Figure 2. Detection of DENV mRNA level produced in C57BL/6 mice. (a) C57BL/6 mice were infected by intracranial route (IC), and euthanized at 3, 5 and 7 days after infection; or the C57BL/6 mice were infected by via subcutaneous and after 14 days were infected again via intracranial and euthanized 7 days after the second infection (SC-IC). Mock animals received inoculum of C6/36 cell supernatant and after 14 days one more inoculum of C6/36 cell supernatant. (b) C57BL/6 mice were infected through via subcutaneous and euthanized at 6 (6 h.p.i.) or 12 hours (12 h.p.i.) or 8 (8 d.p.i.) or 15 days (15 d.p.i.) after infection. Mock animals received inoculum of C6/36 cell supernatant. Statistical analyses were performed with Mann-Whitney non-parametric test. ${ }^{*} \mathrm{p}<0.05$. 
For virus titration in the brain after IC inoculation with 400 p.f.u. of DENV or with C6/36 cell supernatant (mock), C57BL/6 mice were euthanized for removal of the brain on days 3, 5 and 7 post-infection. For the titration of the virus in the brain after SC-IC infection, C57BL/ 6 mice were inoculated via SC with $5 \times 10^{4}$ p.f.u. of DENV or with C6/36 cell supernatant (mock) and 14 days after this infection, the mice were inoculated again via IC with 400 p.f.u. of DENV or with C6/36 cell supernatant (mock) and mice were euthanized for removal of the brain on days 3, 5 and 7 after this second inoculation. For virus titration in the serum, after inoculation via SC with $5 \times 10^{4}$ p.f.u. of DENV or with C6/36 cell supernatant (mock), the serum was collected 3, 5 and 7 days after inoculation. For the seroneutralization test (PRNT50), C57BL/6 mice were inoculated via SC with $5 \times 10^{4}$ p.f.u. of virus or with C6/36 cell supernatant (mock) and serum samples were collected 60 days after inoculation. d.p.i. = days after infection.

There was no difference in lymphocytes counts in infected mice, when compared to noninfected mice (Figure 4(a)). A decrease in the monocytes count was observed 6 hours after infection in mice, when compared to non-infected mice (Figure $4(\mathrm{~b})$ ). In the infected mice there was no difference in the neutrophils count in comparison to the uninfected mice, at the times studied (Figure 4(c)).

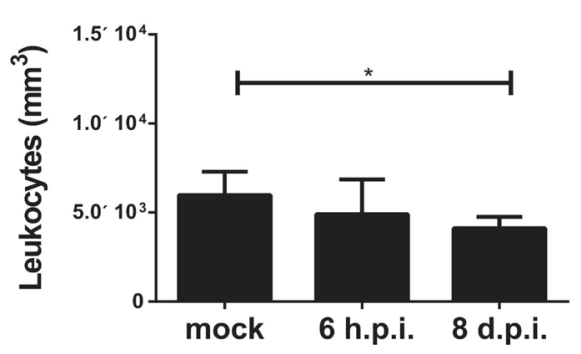

(a)

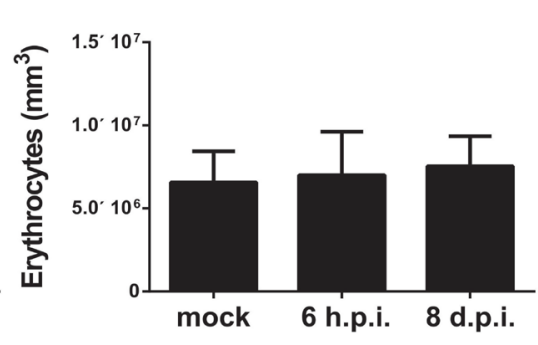

(b)

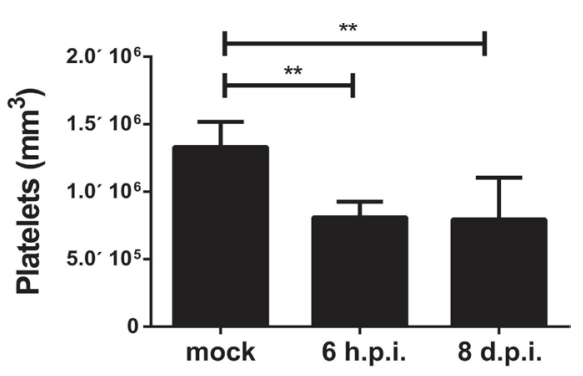

(c)

Figure 3. Leucocytes, red blood cells and platelets count after DENV subcutaneously inoculation. Mice received subcutaneous inoculum of $5 \times 10^{4}$ p.f.u. of DENV, were euthanized 6 hours or 8 days after infection and blood were collected in EDTA tubes for leukocyte, red blood cells and platelets count. h.p.i. = hours post infection; d.p.i. = days post infection. Mock: mice received C6/36 cell supernatant inoculum. Statistical analyses were made with Mann-Whitney non-parametric test. ${ }^{\star} \mathrm{p}<0.05$; ${ }^{\star *} \mathrm{p}<0.01$. (a) mice leukocytes. (b) mice red blood cells. (c) mice platelets.

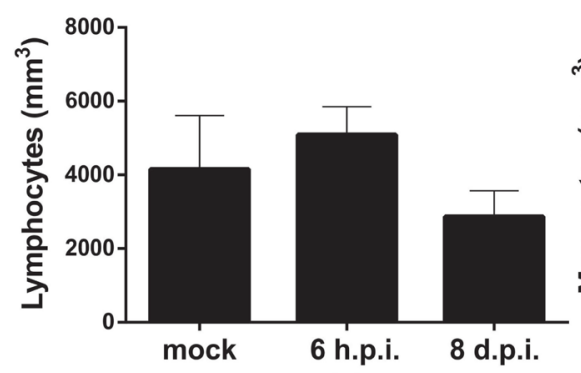

(a)

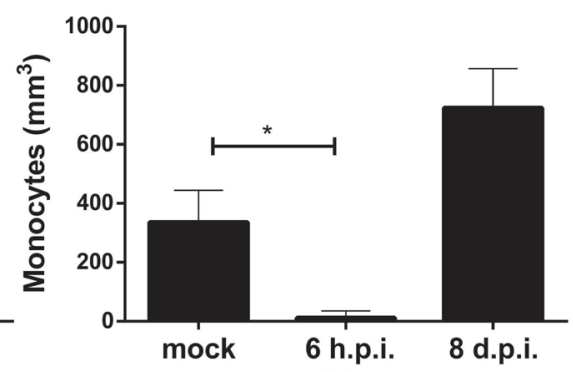

(b)

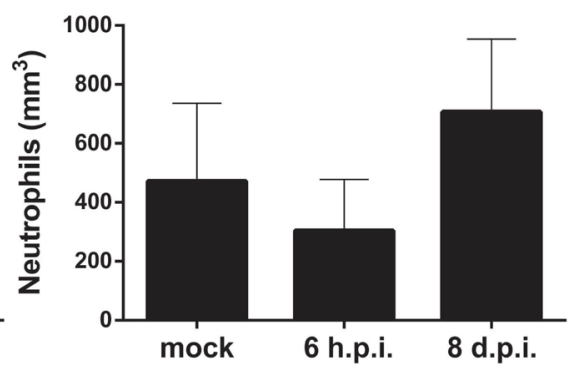

(c)

Figure 4. Lymphocytes, monocytes and neutrophils count after DENV infection. Mice received subcutaneous inoculum of $5 \times 10^{4}$ p.f.u. of DENV and were euthanized 6 hours or 8 days after infection and blood were collected in EDTA tubes for lymphocytes, monocytes and neutrophils count. h.p.i. = hours post infection; d.p.i. = days post infection. Mock: the mice received C6/36 cell supernatant inoculum. Statistical analyses were made with Mann-Whitney non-parametric test. ${ }^{*} \mathrm{p}<0.05$. (a) mice lymphocytes. (b) mice monocytes. (c) mice neutrophils. 


\subsection{Cytokine Levels Increase in the Liver and Spleen of Mice after Subcutaneous Infection}

An increase of TNF alpha level in mice spleen, 6 hours after subcutaneous DENV inoculation was observed, when compared to the uninfected group (Figure 5(a)). An increase of TNF alpha level in mice liver was observed 6 and 12 hours after subcutaneous DENV infection, when compared to the uninfected group (Figure 5(b)). The cytokine IL-12p70 in the liver of infected mice was similar to cytokine level found in uninfected mice at all times studied (Figure 5 (c)). On the other side, IFN gamma in the liver of mice 6 and 12 hours after infection with DENV was increased, when compared to the uninfected mice (Figure 5(d)). In the spleen no IL12-p70 and IFN gamma were detected (data not shown).

\section{Discussion}

Recently, our group presented an experimental model of intracranial (IC) infection with a highly virulent DENV, to study dengue disease with neurologic complications [5] [6]. Here, the intracranial inoculation performed in this work was to compare the weight loss observed with this kind of infection previously described [5] [6] with the weight loss obtained after the subcutaneous inoculation,

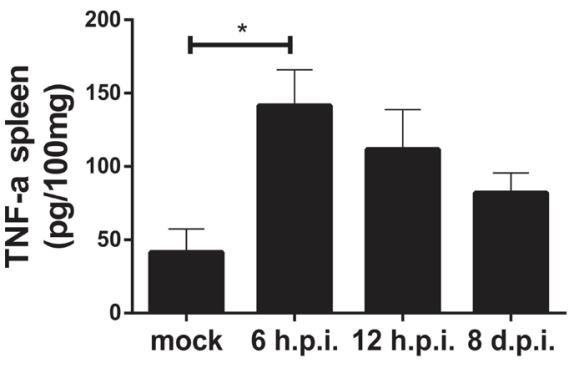

(a)

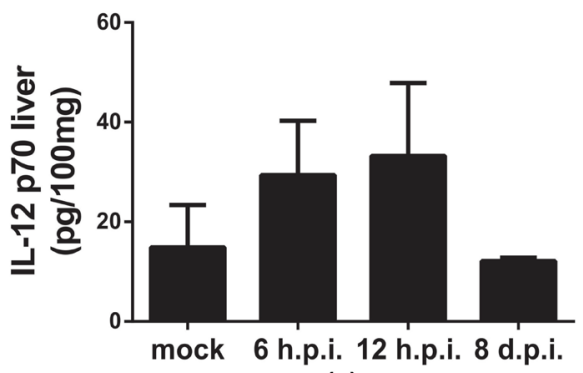

(c)

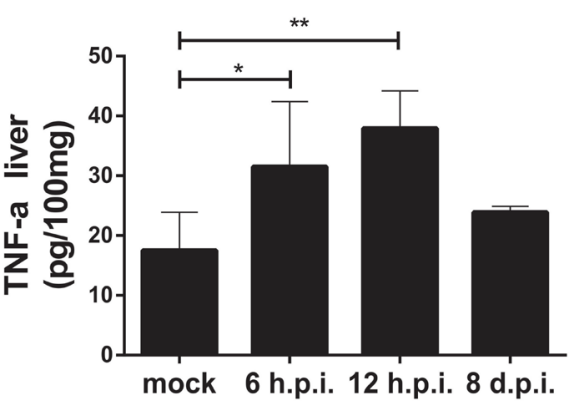

(b)

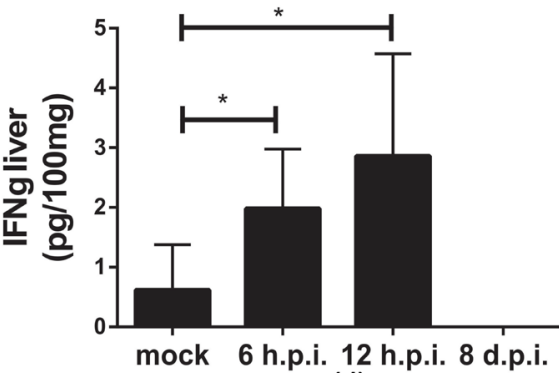

(d)

Figure 5. Cytokines levels on spleen and liver of mice, after DENV inoculum by subcutaneous route. Mice were inoculated via subcutaneous, with $5 \times 10^{4}$ p.f.u. of DENV, euthanized with 6 or 12 hours or 8 days after infection and organs were collected and stored in a protease inhibitor solution. Cytokines were evaluated by flow cytometry beads. (a) TNF alpha levels on mice spleen. (b) TNF alpha levels on mice liver. (c) IL12 p70 on mice liver. (d) IFN gamma on mice liver. Mock: the mice received C6/36 cell supernatant inoculum). h.p.i: hours post infection; d.p.i: days post infection. Statistical analyses were made with Mann-Whitney non-parametric test. ${ }^{*} \mathrm{p}<0.05$; ${ }^{*} \mathrm{p}<0.01$. 
using the same mice sample and the same highly virulent virus. The subcutaneous inoculation is an additional model, using immune competent mice infected with highly virulent virus to study the immune response against dengue, looking for a less aggressive model, when compared to the intracranial inoculation model. The subcutaneously inoculation is also closer to how infections occur in humans, who are infected by mosquito's bites in the skin. While our model is not necessarily better than the humanized mice model, it is an additional model, which is less aggressive than the humanized mice model. And since a loss of weight and subsequent recovery and stabilization of the animals were observed in the subcutaneous infection, although no classic clinical signs occurred, we believed that this model could be useful for the study of dengue disease, for a better understanding of the pathogenesis of the disease. Differently from clinical signs, after SC infection of mice with DENV, hematological and immunological changes of the host were observed, what represents a way to study experimental dengue in mouse. Surprisingly, previous infection of mouse by SC conferred resistance to a subsequent IC infection (Figure 1). It seems that the subcutaneous infection prevents the mice from displaying an exacerbated immune response, resulting in the animal survival. The reason also could be that the antibody neutralization production, as presented in Table 1, could impair the lethality of this highly virulent DENV in the second infection by via IC. In our mouse experimental SC model, the mice suffer a thrombocytopenia (Figure 3(c)) and monocytopenia (Figure 4(b)) since the sixth hour after the infection, besides a leukopenia (Figure 3(a)) from day 8 after infection. Thrombocytopenia occurs in $80 \%$ to $100 \%$ of the dengue patients and leukopenia are a human dengue characteristic also [2] [3] [8] [9] [28] [29]. We showed in our model, that TNF alpha in the spleen and IFN gamma in the liver of immune competent mice 6 hours after infection with DENV have increased (Figure 5(a) and Figure 5(d), respectively), showing the importance of these cytokines to the host defense against a highly virulent dengue virus inoculated by via subcutaneous. It has been reported that the cytokines IFN gamma and TNF alpha are important in the fight against dengue [7] [30]. The model presented in this work presented some but not all of the human manifestations, as all the other models already mentioned in the literature, but it is an additional model, which uses immunocompetent mice, being infected by the subcutaneous via with a highly infective DENV. This model is an additional interesting model for the study of immune responses to dengue virus.

\section{Conclusion}

The study presents an immune competent mice model infected by via subcutaneous with highly virulent DENV. In this model, the cytokine levels and hematological parameters such as global and differential leukocyte and platelets counts, together with weight loss, were considered important parameters, allowing a better understanding of the disease, because these changes occur normally in human beings. Although there are other murine models for the study of 
dengue, none of them shows all characteristics of human disease. Therefore, more than one model to cover several aspects of the disease is necessary. Our model proved to be an effective and less invasive option for studying the effects of highly virulent DENV on the immune response. This model could be used to study the vertebrate immune response, drugs or vaccine against dengue virus as it reproduces some of the clinical symptoms of patients.

\section{Acknowledgements}

The authors thank the program for technological development in tools for health-PDTIS-FIOCRUZ for the use of its facilities.

\section{Fundings}

The PAPES VI/Fiocruz/CNPq (403521/2008-4) to MAC;

CNPq-MCTIC-CNPq/MEC-CAPES/MS-Decit/FNDCT, Prevenção e Combate ao vírus Zika (440911/2016-8) to EGK; FAPEMIG-PPM (00452-17) to EGK; INCTV/FAPEMIG (000077-09) to MAC. AVM, EGK (307423/2015-8) and MAC (307285/2015) are fellows from CNPq.

\section{References}

[1] World Health Organization (WHO). (2016) Technical Handbook for Dengue Surveillance, Dengue Outbreak Prediction/Detection and Outbreak Response ("Model Contingency Plan"). World Health Organization, Geneva.

[2] Xavier, A.R., Freitas, M.S., Loureiro, F.M., Borghi, D.P. and Kanaan, S. (2014) Manifestações clínicas na dengue: diagnóstico laboratorial. Brazilian Journal of Medicine, 102, 7-14.

[3] World Health Organization (WHO). (2012) Handbook for Clinical Management of Dengue. World Health Organization, Geneva.

[4] World Health Organization (WHO). (2009) Dengue Guidelines for Diagnosis, Treatment, Prevention and Control. World Health Organization, Geneva.

[5] Ferreira, G.P., Figueiredo, L.B., Coelho, L.F.L., Junior, P.A.S., Cecilio, A.B., Ferreira, P.C.P., Bonjardim, C.A., Arantes, R.M., Campos, M.A. and Kroon, E.G. (2010) Dengue Virus 3 Clinical Isolates Show Different Patterns of Virulence in Experimental Mice Infection. Microbes and Infection, 12, 546-554. https://doi.org/10.1016/j.micinf.2010.03.007

[6] Souza, K.P.R., Silva, E.G., Rocha, E.S., Figueiredo, L.B., Almeida-Leite, C.M., Arantes, R.M.E., Assis, J.S.G., Ferreira, G.P., Oliveira, J.G., Kroon, E.G. and Campos, M.A. (2013) Nitric Oxide Synthase Expression Correlates with Death in an Experimental Mouse Model of Dengue with CNS Involvement. Virology Journal, 10, 267. https://doi.org/10.1186/1743-422X-10-267

[7] Solomon, T., Dung, N.M., Vaughn, D.W., Kneen, R., Thi, L., Thao, T., Raengsakulrach, B., Loan, H.T., Day, N.P., Farrar, J., Myint, K.S., Warrell, M.J., James, W.S., Nisalak, A. and White, N.J. (2000) Neurological Manifestations of Dengue Infection. Lancet, 355, 1053-1059.

[8] Sahu, R., Verma, R., Jain, A., Garg, R.K., Singh, M.K., Malhotra, H.S., Sharma, P.K. and Parihar, A. (2014) Neurologic Complications in Dengue Virus Infection: A Prospective Cohort Study. Neurology, 83, 1601-1609. 
https://doi.org/10.1212/WNL.0000000000000935

[9] Kutiyal, A.S. (2017) Dengue Haemorrhagic Encephalitis: Rare Case Report with Review of Literature. Journal of Clinical and Diagnostic Research, 11, 10-12.

[10] Barbara, J.B. (1995) Blood Sampling and Film Preparation. Oxford, United Kingdom.

[11] Flemans, F.G.J.H. (1973) As hemácias e suas precursoras. In: Atlas de citologia hematologica. Rio de Janeiro, Brasil.

[12] Flemans, F.G.J.H. (1973) Granulócitos, monócitos, megacariócitos. In: Atlas de citologia hematológica. Rio de Janeiro, Brasil.

[13] Flemans, F.G.J.H. (1973) Linfócitos, plasmócitos e seus precursores. In: Atlas de citologia hematológica. Rio de Janeiro, Brasil.

[14] Zompi, S. and Harris, E. (2012) Animal Models of Dengue Virus Infection. Viruses, 4, 62-82. https://doi.org/10.3390/v4010062

[15] Connell, K.E.O., Mikkola, A.M., Stepanek, A.M., Vernet, A., Hall, C.D., Sun, C.C., Yildirim, E., Staropoli, J.F., Lee, J.T. and Brown, D.E. (2015) Practical Murine Hematopathology: A Comparative Review and Implications for Research. American Association for Laboratory Animal Science, 65, 96-113. https://doi.org/10.1128/JVI.00062-06

[16] Shresta, S., Sharar, K.L., Prigozhin, D.M., Beatty, P.R. and Harris, E. (2006) Murine Model for Dengue Virus-Induced Lethal Disease with Increased Vascular Permeability. Journal of Virology, 80, 10208-10217. https://doi.org/10.1128/JVI.00062-06

[17] Zellweger, R.M. and Shresta, S. (2014) Mouse Models to Study Dengue Virus Immunology and Pathogenesis. Frontiers in Immunology, 5, 1-9.

[18] Costa, V.V., Fagundes, C.T., Souza, D.G. and Teixeira, M.M. (2013) Inflammatory and Innate Immune Responses in Dengue Infection: Protection versus Disease Induction. American Journal of Pathology, 182, 1950-1961.

https://doi.org/10.1016/j.ajpath.2013.02.027

[19] Kenneth, M., Paul, T. and Walport, M. (2010) Imunobiologia de Janeway. Rio Grande do Sul, Brasil.

[20] Palomino, D.C.T. and Marti, L.C. (2015) Chemokines and Immunity. Hospital Israelita Albert Einstein, 13, 469-473. https://doi.org/10.1590/S1679-45082015RB3438

[21] Campos, M.A., Souza, K.P.R., Oliveira, D.B. and Kroon, E.G. (2016) Neurotropic Dengue Virus Infections. In: Neurotropic Viral Infections, Springer International Publishing, Cham, 259-272. https://doi.org/10.1007/978-3-319-33133-1_10

[22] Akkina, R. (2014) Humanized Mice for Studying Human Immune Responses and Generating Human Monoclonal Antibodies. Microbiology Spectrum, 2.

[23] Figueiredo, L.B., Cecílio, A.B., Ferreira, G.P., Drumond, B.P., Oliveira, J.G., Bonjardim, C.A., Ferreira, P.C.P. and Kroon, E.G. (2008) Dengue Virus 3 Genotype 1 Associated with Dengue Fever and Dengue Hemorrhagic Fever, Brazil. Iranian Journal of Microbiology, 5, 314-316.

[24] Russell, P.K., Nisalak, A., Sukhavachana, P. and Vivona, S. (1967) A Plaque Reduction Test for Dengue Virus Neutralizing Antibodies. The Journal of Immunology, 99, 285-290.

[25] Camilla, C., Defoort, J.P., Dellage, M., Auer R.Q.J., Lary, T., Hamelik, R., Prato, S., Casano, B., Martin, M. and Fert, V. (1998) A New Flow Cytometry-Based Multi-Assay System. 1. Application to Cytokine Immunoassays. Cytometry. Supplement, 8, 132.

[26] Stordeur, P., Poulin, L.F., Craciun, L., Zhou, L., Schandené, L., De Lavareille, A., 
Goriely, S. and Goldman, M. (2002) Cytokine mRNA Quantification by Real-Time PCR. The Journal of Immunology Methods, 259, 55-64.

https://doi.org/10.1016/S0022-1759(01)00489-6

[27] Giulietti, A., Overbergh, L., Valckx, D., Decallonne, B., Bouillon, R. and Mathieu, C. (2001) An Overview of Real-Time Quantitative PCR: Applications to Quantify Cytokine Gene Expression. Methods, 25, 386-401.

https://doi.org/10.1006/meth.2001.1261

[28] Lye, D.C., Archuleta, S., Syed-Omar, S.F., Low, J.G., Oh, H.M., Wei, Y., et al. (2017) Prophylactic Platelet Transfusion plus Supportive Care versus Supportive Care alone in Adults with Dengue and Thrombocytopenia: A Multicentre, Open-Label, Randomised, Superiority Trial. The Lancet, 389, 1611-1618.

https://doi.org/10.1016/S0140-6736(17)30269-6

[29] Sarathy, V.V., White, M., Li, L., Gorder, S.R., Pyles, R.B., Campbell, G.A., et al. (2015) A Lethal Murine Infection Model for Dengue Virus 3 in AG129 Mice Deficient in Type I and II Interferon Receptors Leads to Systemic Disease. Journal of Virology, 89, 1254-1266. https://doi.org/10.1128/JVI.01320-14

[30] Neelika, G. and Ogg, G.S. (2013) T Cell Responses in Dengue Viral Infections. Journal of Clinical Virology, 58, 605-611. https://doi.org/10.1016/j.jcv.2013.10.023 